\title{
An Investigation of the correlation between Distributive Justice and Employee Performance considering the Mediating character of Career Incentives: A case study ofCall center industry of Pakistan
}

\author{
Dr. Junaid Athar Khan \\ Assistant Professor Institute of Business Studies and Leadership \\ Abdul Wali Khan University Mardan \\ Junaid@awkum.edu.pk \\ Ms. Sourat Mehr \\ PhD Research Scholar, Institute of Business Studies and Leadership \\ Abdul Wali Khan University Mardan \\ Dr. Naseeb Ullah Shah \\ Abasyn University Peshawar \\ Muhammad Saleem Qazi \\ Visiting Lecturer, Pak Study Department \\ Bahauddin Zakriya University, Multan \\ Saleemtaunsvi82@gmail.com
}

\begin{abstract}
This paper is unique foe being among the few research studies that investigated the impact of distributive justice on employee's performance considering the mediating aspect of economic benefits or career incentives. For this study, 120 call center employees were randomly selected as the participants of this study however, only 112 responses were assumed reliable and trustworthy for further investigation. For the selection of the participants 10 call centers were selected randomly that are operating in the twin - cities (RWP-ISB) of Pakistan. Various analysis including Hierarchical regression, descriptiveand correlation analysis were employed for the investigation of data and for hypothesis testing. Upon the evaluation of the overall findings of this study, A strong positive correlation is discovered between distributive justice and employee's performance. Furthermore, a mediating role of economic benefits or career incentives have been discovered on the relationship between distributive justice and employee's performance. For future research, it is suggested that the researchers should take into account both the organizational features and individual characteristics to get an insight to the the influence of career incentives over performance of employees in an organization. In this regard, an organization should implement a tremendously competitive and effective compensation plan and an attractive remuneration package and some additional employee's incentivesprograms in proximity with the supreme procedures of distributive justice to accomplish long term and consistent sustainability to get desired level of performance.
\end{abstract}




\section{Key Words:}

Career Incentives, Economic/Fringe Benefits, Distributive Justice, Employees Performance, employee's in Cellular Industry.

\section{Introduction}

Employee's performance is highly crucial for a prolonged sustainability and growth of both the small and large sized organizations, especially in the servicing sector across the globe. The success of an organization in the servicing industry is solely based upon the overall attitude and commitments of employees towards their respective organization. There are a number of factors that directly and indirectly affects the performance of employees in a servicing industry that includes both the intrinsic and extrinsic factors, i.e. monetary benefits associated with one's job, recognitions and promotions, etc... However, the economic benefits or compensation offers to the employees has a considerable level of impact over their performance level because in private sector employees are more sensitive towards their pay packages as compared to any other intrinsic motivational factor.

\subsection{Industry Background}

Just like the other developing countries of the world, most of the developed countries started outsourcing their production and servicing concerns to Pakistan, especially in the call center sector. According to the report of PSEB, the call center sector of the country have shown a remarkable growth in 2005, i.e. 110 call centers was established, which were employing more than 2500 agents and generated $\$ 50$ million, which is now reached to $\$ 3$ billion and employing more than 30,000 people (Baloch, 2018). Pakistan has been facing high inflation rate and lower purchasing power of its residents and especially that of the job holder segment of the population. It is also observed that the servicing industry of the country and especially the private firms are facing an issue of lower performance of employees, which is attributed to the lower monetary incentives that this sector is offering to its employees. The industry is expected to further grow with a rapid pace because of the recent reforms of the government regarding the IT sector and establishment of the IT industry in the country, which mean that there would be higher competition and opportunities for employment in this sector.

\subsection{Problem Statement}

Among the various servicing industries of the country, the rapidly declining performance of employees in the Call Center Industry of Pakistan has caused a set back into this sector, especially in terms of compromise over the quality of work and organizational performance both in terms of its operations and profitability. A number of past studies have provided that the challenges concerning performances of organizations are mostly associated with poor compensation and application of the out dated employees retention and recruitment strategies, lack of employees involvement in the process of decision making, failure of organizations to create and implement rational decisions and poor working environment(Khan \& Du, 2014). It is 
also possible that organizational success can be attained with the help of an effective coordination between the systems and individuals responsible for running these systems and therefore, they need to possess the required knowledge and skills to execute planning and strategy in an organization. Recent studies and evaluations of the psychologists have noted that majority of the youngsters working in the call center industry are highly vulnerable to burn-out-stress syndrome (BOSS), symptoms of which includes sleeplessness, problems with digestive system and constant exhaustion, which in turns affects the quality and cost of the service. The attitude and frustration level of employees differ from region to region because one of the exclusive characteristics of call center is that they observe the holidays schedule of their clients instead of the holidays of their own country, which in turns negatively affects the motivation level of their employees towards the organization (M. Imran Malik, 2011).

\subsection{Purpose of The Study}

The basic objective/purpose of this research is to evaluate the impact of distributive justice over the performance of employees in the call center industry of Pakistan while keeping in view the mediating role of the economic benefits offered to such employees. The study is aimed to understand the overall organizational structure and performance matrices of the call center industry of Pakistan. It is also aimed to build an understanding about the various economic benefits that are offered to the employees of call center industry and how these benefits impact the role of distributive justice in building employees performance.

\subsection{Research Question}

Based upon the basic purpose of this study and the underlying problem statement, this research is bent to provide answers to the following two questions:

- Whether economic benefits offered to the employees have an impact in shaping the correlation between distributive justice and employee's performance?

- Is there a correlation between the distributive justice and performance of employees in the call center industry of Pakistan?

This research will contribute effectively in unrevealing secrets behind the enhancement of employee's performance and contributes to the present body of knowledge on distributive justice and its impact upon employee's performance.

\section{Literature Review}

\subsection{The role of Distributive Justice in Improved Employee Performance}

According to Greenberg, (1990) distributive justice can be defined as a variant of organizational justice that refers to the equal distribution and allocation of resources in an organization. Whereas Janssen (2004) defined distributive justice as the perception of employees of an organization regarding the extent of the investments made in a particular period of time and 
the associated benefits/compensation to it. Distributive justice is not limited to the distribution of money/payments only rather it has a broader sense that include various organizational outcomes such as work programs, promotions, compensation and benefits, punishments, and performance evaluation.

Distributive justice has a positive relationship with employee performance because it is stem from equity theory. As indicated by equity theorists, people analyze a proportion of their perceived contributions to results procured from a correlation with that of a referent other. In the event that the proportions are equivalent, the individual perceive fairness in distributive justice. On the other hand, if the proportions are disparate, an inequity in distributive justice will be perceived by an individual (Abu Elanain, 2010).

According to the study of the Jawahar (2002) employee get direct impact from the condition of equity in an organization therefore, according to equity theory, employees have an ability to adjust the quality and quantity of their work according to the condition of justice in their respective organizations. McCain et al., (2010) further argued that when employee found that an organization is not practicing the justice in its procedures and day to day business operations, they are less likely to pay attention to their work, performance, and to things that could balance everything rather they focus on their own interests on the expanse of organization. On the other hand, when an organization has fair organizational justice, where it treats all of its employees fairly, the employees are more likely to give importance to the interests of the organization over their own individual interests. Nabatchi et al., (2007) found that employee contribute high in the success of their organization, when they feel that organization has fair organizational justice.

Abu Elanain, (2010); Folger, (1987); and Johnson, Selenta\& Lord, (2006) also found that distributive justice leads to improved employee performance and organizational effectiveness.

\subsection{The Impact of Economic Benefits on Employee Performance}

Economic benefits in an organization refer to economic value that employees receive in recognition to their exceptional performance or good conduct other than their basic salary or wages. Economic benefits are actually an investment in human capital that helps in improving the overall performance of employees and organization (López-Bazo\& Moreno, 2008). Economic benefits in the form of rewards and compensation are motivational factors for employees in an organization (A, 2016). According to Gubler, Pierce \& Nickerson, (2013) rewards can be categorized in two types: intrinsic rewards and extrinsic rewards. Intrinsic rewards are basically non-monetary rewards that are related to the job itself such as high satisfaction and appraisal from others upon completing a task or achieving something. Whereas extrinsic rewards are external to the job and are offered by organization such as salary, medical allowance, insurance, job security, promotion and fringe benefits etc. Rewards like good salary, bonus, promotions, and recognition are the mediating factors between organizational justice and employee performance (Cameron \& Pierce, 1994).

Cameron \& Pierce, (1994) and A,(2016) have found in their studies that for getting higher employee performance, employees needs to be motivated enough, and economic benefits 
offered by organizations are the best motivational tools that motivate employees to perform at their best regardless of working conditions.

\subsection{The Relationship between Economic Benefits and Distributive Justice}

A strong relationship between organizational reward policies and distributive justice has been found because the fairness of economic benefit policies is dependent on the fairness of distributive justice. Perception regarding the unequal distributions of rewards among employees by comparison with others result in tension among employees for which they become demotivated to perform at their full potential (Al-Zu'bi, 2010). According to the study of Mosadeghrad, (2003) the unfair distribution of reward benefits results in lower organizational commitment, low self-esteem, poor performance, and high turnover intentions. Job satisfaction and employee performance has a positive correlation, while job satisfaction is identified as a multifaceted component of employee's feeling, as it is comprised of both intrinsic and extrinsic components of a job (Misener et al., 1996).

The positive correlation between job satisfaction and distributive justice has also shown a positive relationship with high employee's performance. Employees that are highly satisfied are more likely to participate in the process of decision-making of an organization as well as are contributing efficiently in the work processes to help organization in accomplishing its goals (Olkkonen\&Lipponen, 2006).

\subsection{Theoretical Framework} framework:

Based upon the above discussion the researcher has developed the following research

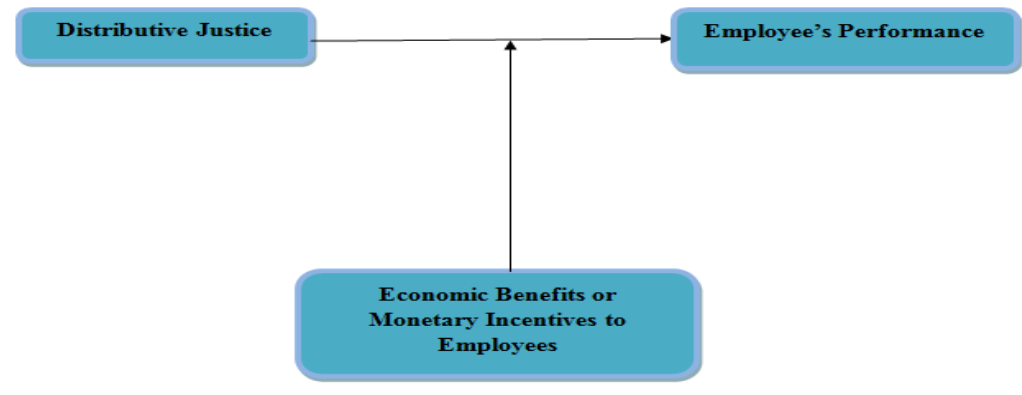

Figure - 1: Research Framework study:

On the basis of the research framework, the following hypothesis are generated for this

H1: Distributive justice is positively connected to the performance of employees.

$\mathrm{H} 2$ : The correlation between distributive justice and employee's performance is mediated by the economic benefits or monetary incentives offered to employees. 


\section{Methodology}

The researcher has adopted quantitative method with cross sectional survey design for the execution of this study. Research design of this study enabled the researcher in collecting and analyzing the data to identify the impacts of distributive justice over the performances of employees with mediation of the monetary incentives/economic benefits. The researcher used close ended questionnaires for measuring and obtaining the responses from the participants regarding the key variables of the study, i.e. distributive justice, employee's performance and monetary incentives/economic benefits offered to the employees.

Table - 1: Distribution of Variables

\begin{tabular}{cccc}
\hline Variables & No of Items & Scales & References \\
\hline Distributive Justice & Four & Likert Scale 1-5 & $\begin{array}{c}\text { (Hsu, Jiang, Klein \& } \\
\text { Tang, 2003) }\end{array}$ \\
Employees & Five & Likert Scale 1-5 & $\begin{array}{c}\text { (Reisel, Probst, Chia, } \\
\text { Maloles\& König, } \\
\text { Performance }\end{array}$ \\
& & 2010) \\
Monetary & Seven & Likert Scale 1-5 & (Reisel, Probst, Chia, \\
Incentives/Economic & & Maloles\& König, \\
Benefits & & 2010) \\
\hline
\end{tabular}

The questionnaire consists upon 20 questions, where four questions belonged to demographic section; four were asked for distributive justice; five for employee's performance and seven for monetary incentives/economic benefits offered to employees. The replies from the respondents were measured/analyzedusing a five point Likert scale, where $1=$ strongly agree and $5=$ strongly disagree.

\subsection{Population and Sample Size}

Researcher has selected 10 call centers from the twin - cities (RWP-ISB) of Pakistan, where all the employees of these call centers were taken as the population of this study, hence the total population was about 370 . Out of this population a sample of 120 employees was drawn, where 12 employees were selected from each call center on random basis, so that each employee in the population will enjoy an equal chances of selection into the given sample size. A set of 120 questionnaires was distributed among the selected samples, but only 115 replies were received out of which the responses of only 112 participants were assumed reliable and trustworthy for carrying out additional investigation. The reliability of questionnaire was evaluated with the help of Alpha Coefficient or Cronbach's Alpha, which indicated the internal consistency of the questionnaire, the results of such test are given as under:

\section{Table -2 : Reliability Statistics}




\begin{tabular}{ccc}
\hline Measure & No. of Items & Cronbach's Alpha \\
\hline Distributive Justice & 4 & 0.882 \\
Employee Performance & 5 & 0.759 \\
$\begin{array}{c}\text { Monetary Incentives/Economic } \\
\text { Benefits }\end{array}$ & 7 & 0.800 \\
\hline
\end{tabular}

Factor analysis was conducted on this study to evaluate the extent of relationship between the three variables on the given questionnaires and found that the results are appropriate, i.e. the $\mathrm{KMO}$ value if 0.741 and $\mathrm{p}=.000$, indicating significant Bartlett's Test of Sphericity as provided in the given table:

Table - 3: Factor Analysis

\begin{tabular}{lcc}
\hline \multicolumn{2}{l}{ KMO (Kaiser - Meyer - Olkin Measure of Sampling } & 0.741 \\
Adequacy) & & \\
\hline Bartlett's Test of Sphericity & Approx. Chi-Square & 194.986 \\
& DF & 09 \\
& Sig. & 0.000 \\
\hline
\end{tabular}

\section{Analysis}

The analysis of the collected responses from the participants would help the researcher in determining the correlation between distributive justice and employee's performance with the mediation role of monetary incentives or economic benefits offered to the employees.

\subsection{Analysis of the Demographic data}

The researcher found that response rate from senior staff members having ages of above 40 was about $26.7 \%$, while the respondents below 30 was $73.3 \%$. It is because of the fact that majority of the call center jobs are very tough and have some hectic routine and only youngsters can cope with such working environment. About $65 \%$ of the respondents were female and $35 \%$ were male because majority of the call centers prefer to hire female staff members because they are found as more persuading or having comparatively higher customer representation skills. With respect to the education level, majority of the participants were the graduates of high school or university graduates, i.e. $35 \%$ and $45 \%$ respectively, while the rest of $20 \%$ were having lower qualification. With respect to occupation, majority of the employees were from tactical level of the organization, i.e. $98 \%$.

\subsection{Descriptive analysis of the variables}


The following table exhibits the descriptive analysis of all the three variables:

Table - 4: Descriptive statistics of variables

\begin{tabular}{ccccccc}
\hline & N & Minimum & Maximum & Mean & $\begin{array}{c}\text { Std. } \\
\text { Deviation }\end{array}$ & Skewness \\
\hline DJ & 112 & 2 & 5 & 3.487 & 0.986 & -0.203 \\
EB & 112 & 1 & 5 & 3.791 & 0.627 & -0.762 \\
EP & 112 & 2.14 & 5 & 4.621 & 0.577 & -1.000 \\
\hline
\end{tabular}

Note: $\mathrm{DJ}=$ Distributive Justice, $\mathrm{EB}=$ Economic Benefits offered to employees and $\mathrm{EP}=$ Employees performance

The given tables showed that means of the variables are ranging from 3.487 to 4.621 , which shows that the values of all the variables are ranging from moderately high to the highest one. It also shows that the distributive justice has the lowest mean value with a standard deviation of 0.986 , which is followed by economic benefits offered to the employees and the employee performance with the highest value.

\subsection{Correlation Analysis}

The correlation analysis is included to indicate the direction or intensity of the linear correlation between the given variables. The results are shown in the table below:

Table - 5: Correlation Analysis

\begin{tabular}{ccc}
\hline & $\mathbf{1}$ & $\mathbf{2}$ \\
\hline Distributive Justice & - & \\
Employees Performance & $0.392^{* *}$ & - \\
$\begin{array}{c}\text { Economic Benefits/Monetary } \\
\text { Incentives }\end{array}$ & $0.251^{* *}$ & $0.628^{* *}$ \\
\hline
\end{tabular}

The table shows that the relationship between the various variables of the research are help in expected direction, the dependent variable performance of employees correlated with the independent variable distributive justice, i.e. $\mathrm{r}=0.392, p<.01$, while for distributive justice $\mathrm{r}=$ $0.251, p<0.1$. Here it is found that the mediating role of the monetary incentives or economic benefits correlates with the independent variable and it also correlates with the dependent variable, hence hypothesis 2 is also accepted.

Table - 6: Regression Analysis 


\begin{tabular}{|c|c|c|c|c|c|}
\hline & \multicolumn{2}{|c|}{$\begin{array}{l}\text { Unstandardized } \\
\text { Coefficients }\end{array}$} & Standardized Coefficients & $\mathbf{T}$ & Sig. \\
\hline & $\begin{array}{l}\beta \\
2.403\end{array}$ & $\begin{array}{l}\text { Std. Error } \\
.475\end{array}$ & Beta & 5.405 & .000 \\
\hline EB & .517 & .138 & .527 & 4.391 & .000 \\
\hline $\mathbf{E P}$ & .291 & .169 & .280 & 3.398 & .000 \\
\hline \multicolumn{4}{|c|}{ Adjusted R Square $=0.392$} & & \\
\hline
\end{tabular}

The results showed that there is significant positive relationship between the distributive justice and employee's performance, while the mediating variable economic benefits or monetary incentives also showed significant relationship with both the dependent and independent variables, i.e. $\beta=2.403$ and 0.291 , respectively. Furthermore, the independent variable distributive justice can cause variations into the dependent variable employee's performance up to the extent of $39.2 \%$, which shows that a unit change in independent variable can cause a corresponding change of $30.2 \%$ in the dependent variable.

\section{Discussion}

The basic objective of this research was to investigate the connection between employee's performance and distributive justice, while investigating the mediating role of monetary incentives or economic benefits in establishing relationship among these two variables. The researcher found that distributive justice has a significantly positive relationship with the employee's performance. Whereas, the study conducted by Reisel, Probst, Chia, Maloles\& König, (2010) and Hsu, Jiang, Klein \& Tang, (2003) found similar results with the given study. The result of this study is also consistent with the studies of Khan \& Du, (2014), M. Imran Malik, (2011)and Gubler, T., Pierce, L., \& Nickerson, J. (2013). This evaluated that organizations can improve the performances of their employees through offering them better economic benefits or monetary incentives because employees in private sector organization and especially in organizations like call centers do not expect a long term association or career growth. Unlike other larger conglomerates or public sector organizations, employees in call center industry do not look for a career growth related incentives rather they simply measure their advantage or benefit in terms of the extent of monetary benefits that they can gain from an organization. The findings obtained by the regression analysis shows that economic benefits partially mediates the correlation between distributive justice and employees performance as the variable met all the four conditions of mediation. This means that employees feel motivated towards their work if they feel that the monetary incentives or economic benefits are justly distributed among all the employees of an organization. The findings of this study is therefore, consistent with the expectation or equity theory, which also states that employees will be motivated if they are given just and fair compensation with respect to the extent of work that they do for their organization.

\section{Conclusion}


This study expanded the knowledge and research work on the role of distributive justice in shaping the overall performance level of employees of an organization and the importance of inclusion of better compensation system that can help the employees in meeting their daily needs. The findings of this study evaluated that it is highly crucial for organizations to put in place better compensation systems in their organizations to motivate their employees and improve their performances in the long run. This study can serve as a guide for the management of private sector organizations, especially the call centers to build up a competitive compensation plan for their employees to get an enhanced level of performance output in the long run. Such initiatives will help in achievement of positive attitudinal or behavioral out comes from employees, which will inspire them towards supporting their organizations with their full potential. On the basis of the given discussion, it is concluded that there is a significant positive relationship between distributive justice and employee's performance, if the employee's monetary compensation is increased and distributed among all employees on just and equitable grounds. However, using the monetary or economic benefits as mediating factor only restricts the findings of the study to this variable and neglected the other dimensions of the career incentive plans. Therefore, future researchers should focus upon other dimensions of the career incentive plans implemented by the employers in private sector organizations and their corresponding compliance with the code of corporate governance. 


\section{References}

A, I. (2016).Impact of Extrinsic Rewards on Employees' Performance. Journal of Global Economics, 4(3). http://dx.doi.org/10.4172/2375-4389.1000203

Abu Elanain, H. (2010). Testing the direct and indirect relationship between organizational justice and work outcomes in a non-Western context of the UAE. Journal of Management Development, 29(1), 5-27. http://dx.doi.org/10.1108/02621711011009045

Al-Zu'bi, H. (2010). A Study of Relationship between Organizational Justice and Job Satisfaction. International Journal of Business and Management, 5(12). http://dx.doi.org/10.5539/ijbm.v5n12p102

Baloch, F. (2018).Pakistan, the next outsourcing hub? - Profit by Pakistan Today. Retrieved from https://profit.pakistantoday.com.pk/2018/06/25/pakistan-the-next-outsourcing-hub/

Cameron, J., \& Pierce, W. (1994). Reinforcement, Reward, and Intrinsic Motivation: A MetaAnalysis. Review of Educational Research, 64(3), 363. http://dx.doi.org/10.2307/1170677

Chen McCain, S., Tsai, H., \&Bellino, N. (2010).Organizational justice, employees' ethical behavior, and job satisfaction in the casino industry. International Journal of Contemporary Hospitality Management, 22(7), 992-1009. http://dx.doi.org/10.1108/09596111011066644

Colquitt, J. (2001). On the dimensionality of organizational justice: A construct validation of a measure. Journal of Applied Psychology, 86(3), 386-400. http://dx.doi.org/10.1037//00219010.86.3.386

Eberlin, R., \& Tatum, B. (2005).Organizational justice and decision making. Management Decision, 43(7/8), 1040-1048. http://dx.doi.org/10.1108/00251740510610035

Folger, R. (1987). Distributive and procedural justice in the workplace. Social Justice Research, 1(2), 143-159. http://dx.doi.org/10.1007/bf01048013

Greenberg, J. (1990). Organizational Justice: Yesterday, Today, and Tomorrow. Journal of Management, 16(2), 399-432. http://dx.doi.org/10.1177/014920639001600208

Gubler, T., Pierce, L., \& Nickerson, J. (2013). What Drives Employee Performance? Evidence on Extrinsic and Intrinsic Motivation. Academy of Management Proceedings, 2013(1), 1447214472. http://dx.doi.org/10.5465/ambpp.2013.14472symposium

Hsu, M., Jiang, J., Klein, G., \& Tang, Z. (2003).Perceived career incentives and intent to leave. Information \& Management, 40(5), 361-369. doi: 10.1016/s0378-7206(02)00018-6

Janssens, M. (1994).Evaluating international managers' performance: parent company standards as control mechanism. The International Journal of Human Resource Management, 5(4), 853-873. http://dx.doi.org/10.1080/09585199400000069

Johnson, R., Selenta, C., \& Lord, R. (2006). When organizational justice and the self-concept meet: Consequences for the organization and its members. Organizational Behavior and Human Decision Processes, 99(2), 175-201. http://dx.doi.org/10.1016/j.obhdp.2005.07.005 
Journal of Business and Tourism

Volume 06 Number 01

January - June, 2020

Khan, M., \& Du, J. (2014).An Empirical Study of Turnover Intentions in Call Centre Industry of Pakistan. Journal Of Human Resource And Sustainability Studies, 02(04), 206-214. doi: $10.4236 /$ jhrss.2014.24021

López-Bazo, E., \& Moreno, R. (2008). Does human capital stimulate investment in physical capital?. Economic Modelling, 25(6), 1295-1305. http://dx.doi.org/10.1016/j.econmod.2008.04.008

M. Imran Malik. (2011). A study of work environment and employees' performance in Pakistan.AFRICAN JOURNAL OF BUSINESS MANAGEMENT, 5(34).doi: 10.5897/ajbm11.1502

McDowall, A., \& Fletcher, C. (2004). Employee development: an organizational justice perspective. Personnel Review, 33(1), 8-29. http://dx.doi.org/10.1108/00483480410510606

Misener, T., Haddock, K., Gleaton, J., \& Abu Ajamieh, A. (1996).Toward an International Measure of Job Satisfaction. Nursing Research, 45(2), 87-91. http://dx.doi.org/10.1097/00006199-199603000-00006

Olkkonen, M., \&Lipponen, J. (2006).Relationships between organizational justice, identification with organization and work unit, and group-related outcomes. Organizational Behavior and Human Decision Processes, 100(2), 202-215. http://dx.doi.org/10.1016/j.obhdp.2005.08.007

Reisel, W., Probst, T., Chia, S., Maloles, C., \& König, C. (2010).The Effects of Job Insecurity on Job Satisfaction, Organizational Citizenship Behavior, Deviant Behavior, and Negative Emotions of Employees. International Studies Of Management \& Organization, 40(1), 7491. doi: 10.2753/imo0020-8825400105

Renn, R., Steinbauer, R., \&Fenner, G. (2014). Employee Behavioral Activation and Behavioral Inhibition Systems, Manager Ratings of Employee Job Performance, and Employee Withdrawal. Human Performance, 27(4), 347-371. http://dx.doi.org/10.1080/08959285.2014.929694 